\title{
The minor allele of the PPAR $\gamma 2$ Pro12Ala polymorphism is associated with lower postprandial TAG and insulin levels in non-obese healthy men
}

\author{
Ulf Helwig ${ }^{1,2}$, Diana Rubin ${ }^{1,2}$, Julia Kiosz ${ }^{1}$, Stefan Schreiber $^{3}$, Ulrich R. Fölsch ${ }^{2}$, Michael Nothnagel ${ }^{4}$, \\ Frank Döring ${ }^{5}$ and Jürgen Schrezenmeir ${ }^{1}$ \\ ${ }^{1}$ Federal Research Centre for Nutrition and Food, Location Kiel; Hermann-Weigmann Str.1, 24103 Kiel, Germany \\ ${ }^{2}$ First Department of Medicine, University Hospital Schleswig-Holstein, Schittenhelmstr.12, 24105 Kiel, Germany \\ ${ }^{3}$ Institute for Clinical Molecular Biology, University Hospital Schleswig-Holstein, Schittenhelmstr.12, 24105 Kiel, Germany \\ ${ }^{4}$ Institute of Medical Informatics and Statistics, University Hospital Schleswig-Holstein, Brunswiker Str. 10, 24105 Kiel, Germany \\ ${ }^{5}$ Department of Molecular Nutrition, Christian-Albrechts-University, Kiel, 24103 Kiel, Germany
}

(Received 29 June 2006 - Revised 15 November 2006 - Accepted 16 November 2006)

\begin{abstract}
The PPAR $y$ Pro12Ala polymorphism has been associated in several studies with a decreased risk of obesity, type 2 diabetes and insulin resistance. Weak hints are available about the influence of PPAR $\gamma$ Pro12Ala on postprandial metabolism. In 708 men, aged 45 to 65 years the PPAR 22 Pro12Ala genotypes were determined and postprandial TAG, insulin, glucose and NEFA after a standardized mixed fat meal and insulin and glucose after a glucose load (oral glucose tolerance test; OGTT) were assessed. Using the total sample, we did not find a significant impact of the genotype on the postprandial metabolism. In the subgroup with BMI $<30 \mathrm{~kg} / \mathrm{m}^{2}$, fasting and postprandial TAG and insulin levels as well as homeostasis model assessment of insulin resistance (HOMA) were significantly lower in the Ala12Ala group than in the Pro12Pro group after the mixed meal. In contrast, the groups did not differ in insulin levels and HOMA after the OGTT. To investigate if differences between a fat-containing meal and OGTT are caused by adiponectin, we examined a BMI- and age-matched subgroup. No differences were found between the genotypic groups. The effects of the PPAR $\gamma 2$ polymorphism on insulin sensitivity are mediated by affluent dietary fat. We did not find evidence that adiponectin as a fatty-acid-dependent adipocyte factor is a causative factor for this phenomenon.
\end{abstract}

PPAR $\gamma 2$ Pro12Ala: Insulin resistance: Type 2 diabetes: Single nucleotide polymorphism: Adiponectin

PPAR- $\gamma$ is a transcriptional factor that belongs to the family of nuclear receptors such as steroid and thyroid hormone receptors (Desvergne \& Wahli, 1999). PPAR $\gamma$ forms heterodimers with the retinoid-x-receptor and binds to specific PPARresponse elements of DNA (Spiegelman, 1998). Through this mechanism, PPAR $\gamma$ regulates the transcription of different target genes (Spiegelman, 1998). PPAR $\gamma$-regulated genes play a role in fatty acid transport, binding, oxidation and regulation (Desvergne \& Wahli, 1999) and also in inflammatory response (Jiang et al. 1998). Ligands for PPAR $\gamma$, such as troglitazone, are used in clinical practice as insulin sensitizing drugs (Sewter \& Vidal-Puig, 2002). Two main isoforms of PPAR $\gamma$ are known: PPAR $\gamma 1$; PPAR $\gamma 2$. PAPR $\gamma 1$ is present in most tissues, whereas PPAR $\gamma 2$ is predominantly expressed in adipose tissue (Vidal-Puig et al. 1997). A single nucleotide polymorphism, at codon 12 of the exon 1 of PPAR $\gamma 2$, which leads to a switch of the amino acid proline to alanine, has recently been detected (PPAR 22 Pro12Ala) (Yen et al. 1997). In several studies, the PPAR $\gamma 2$ alanine coding genotype was associated with a diminished risk of the development of type 2 diabetes (Koch et al. 1999; Altshuler et al. 2000; Jacob et al. 2000; Ek et al. 2001; Gonzalez-Sanchez et al. 2002). In accordance with this, several studies have shown an association with fasting glucose and TAG and insulin levels; however, an absent association has also been reported (Poirier et al. 2000; Vaccaro et al. 2002). At present, the reasons why diabetes, TAG and insulin resistance are associated with the PPAR $\gamma 2$ Pro12Ala polymorphism remain to be elucidated.

The induction of PPAR $\gamma 2$-regulated gene products in adipocytes such as lipoprotein-lipase (Schoonjans et al. 1996), apo CIII (Hertz et al. 1995), adipocyte lipid-binding protein (aP2) (Tontonoz et al. 1994; Li \& Lazar, 2002), fatty acid binding proteins (Issemann et al. 1992; Darimont et al. 1998), acyl-CoA binding protein (Nitz et al. 2005), acylCoA synthetase (Schoonjans et al. 1995), glycerophosphat dehydrogenase (Li \& Lazar, 2002), diacylglycerol acyltransferase (Li \& Lazar, 2002) and carnitine-palmitoyl transferase (Brandt et al. 1998; Mascaro et al. 1998; Yu et al. 1998; Li \& Lazar, 2002) may result in increased lipid uptake, storage and metabolism in these cells. As a result of this, NEFA release may be reduced. Lower NEFA result in higher insulin sensitivity in muscle tissue (Roden et al. 1996). Indeed, lower fasting (Temelkova-Kurktschiev et al. 2004; Tan et al. 2006) and postprandial NEFA concentrations (Tan et al. 2006) were found after a mixed meal in carriers of the

Abbreviations: AUC, area under the curve; HOMA, homeostasis model assessment of insulin resistance; OGTT, oral glucose tolerance test.

* Corresponding author: Dr Ulf Helwig, fax +49 431609 2472, email ulf.helwig@bfel.de 
alanine coding genotype, compared with Pro12Pro homozygotes. However, other studies showed no differences in the NEFA fasting concentrations of proline $v$. alanine coding genotypes (Stumvoll \& Haring, 2002; Vaccaro et al. 2002; Vänttinen et al. 2005). In another study, the postprandial TAG, glucose and insulin after a fat ingestion and, in comparison, after a glucose load, were investigated in a young European cohort (Poirier et al. 2000). Under both meal conditions, no difference was found between the fasting and postprandial metabolic parameters of the different genotypes. The frequency of this single nucleotide polymorphism, however, considerably varied between cohorts from different European countries. Moreover, only young subjects with a low BMI were analysed. Recently published data from the Bogalusa Heart Study suggests that the association between insulin resistance and the PPAR $\gamma 2$ Pro12Ala polymorphism depends on the individual's age (Li et al. 2003). Insulin resistance was associated with the PPAR $\gamma 2$ Pro12Ala polymorphism in adults, whereas differences in young people were less pronounced. We therefore evaluated the role of the PPAR $\gamma 2$ Pro12Ala polymorphism in the postprandial metabolism of insulin and TAG in a regional cohort with people aged $45-65$ years.

\section{Research design and methods}

\section{Subjects}

The Metabolic Intervention Cohort Kiel is dedicated to the study of gene-nutrient interaction with a particular emphasis on dietary fat, postprandial lipid metabolism and the metabolic syndrome (Syndrome X). A total of 722 men, aged 45 to 65 years, were recruited with the aid of the registrar of the city and surrounding area of Kiel, Germany. Patients with known diabetes, intestinal absorption disorders, liver diseases, renal diseases and intestinal surgical interventions within the last 3 months, thyroid disorders or hormone therapy were excluded. The volunteers underwent a clinical examination including a measurement of pulse, blood pressure, weight, height, waist circumference and hip circumference (World Health Organization, 1995; Lahti-Koski et al. 2000). Fasting plasma levels of TAG, cholesterol, LDL, HDL, insulin, glucose, glutamate oxalacetate transaminase, glutamate pyruvate transaminase, cholinesterase, alkaline phosphatase, C-reactive protein and blood cell count were assessed. Subjects underwent an oral glucose tolerance test and an oral metabolic tolerance test on different days with a minimum of $2 \mathrm{~d}$ in between tests. The local ethics committee approved the study design (AZ: A106/03 from 16 April 2003). The present study was performed according to the Declaration of Helsinki and informed consent was obtained from all subjects.

In the present study, data were only used from those subjects ( $n$ 708) for whom a complete dataset was available.

\section{Oral metabolic tolerance test}

To investigate the influence of a mixed meal on postprandial metabolism, we performed an oral metabolic tolerance test as described elsewhere (Schrezenmeir et al. 1992). This metabolic tolerance test is similar to a normal
Western-style fat-containing diet and allows the investigation of the physiological metabolic response. In brief, after a 12-h fasting period and after taking a fasting blood sample, a standardized liquid mixed meal containing $51.6 \mathrm{~kJ} \%$ fat, $29.6 \mathrm{~kJ} \%$ carbohydrates, $11.9 \mathrm{~kJ} \%$ protein, with a total of $4406 \mathrm{~kJ}$, was ingested within $5 \mathrm{~min}$. At time points $0.5,1,2,3,4$ and $5 \mathrm{~h}$ after ingestion had started, blood samples were taken for the analysis of serum insulin, glucose and TAG, NEFA and adiponectin, and 6, 7, 8 and $9 \mathrm{~h}$ after ingestion, for the analysis of serum TAG, NEFA and adiponectin.

\section{Oral glucose tolerance test}

To investigate the influence of the singular ingestion of carbohydrates on postprandial metabolism for detection of insulin resistance, we performed an oral glucose tolerance test according to the guidelines of the American Diabetes Association (2004). The blood sampling was extended up to $4 \mathrm{~h}$. In short, the volunteers were examined after a 12-h fasting period. Fasting blood samples were collected and $75 \mathrm{~g}$ glucose, dissolved in $250 \mathrm{ml}$ water, was ingested within $5 \mathrm{~min}$. At time-points $0 \cdot 5,1,2,3$ and $4 \mathrm{~h}$ after ingestion had started, blood samples were taken.

\section{Plasma and serum samples}

Blood was taken on ice and centrifuged, and plasma and serum were deep frozen for later analysis. Serum was used for insulin, TAG and NEFA determination, fluorideplasma for glucose determination and EDTA plasma with aprotinin was used for adiponectin determination. Leukocytes and haemoglobin were assessed in EDTA blood. Other parameters were assessed in lithium-heparin plasma. Insulin levels were determined by RIA, according to the instruction manual of the producer (Adaltis, Bologna, Italy). Adiponectin levels were determined by ELISA, according to the instruction manual of the producer (R\&D Systems, Minneapolis, MN, USA). Other parameters were measured enzymatically using a clinical laboratory analyser (Konelab, Espoo, Finland), according to the producer's manual.

\section{Genotyping}

Genomic DNA was isolated from $10 \mathrm{ml}$ frozen blood samples using the Gigakit DNA extraction kit (Invitec, Berlin, Germany). Taqman probes and primers (hcv 1129864) were designed by the supplier (Applied Biosystems, Foster City, CA, USA). Taqman analysis was performed as described elsewhere (Hampe et al. 1999). In brief, genomic DNA was arrayed and dried on 96-well plates. Taqman PCR was set up with Genesis pipetting robots (Tecan, Männedorf, Switzerland). We amplified samples with ABI 9700 PCR machines (Applied Biosystems) and measured fluorescence with ABI 7700 and ABI 7900 fluorometers (Applied Biosystems).

\section{Data analysis}

SPSS (SPSS for windows, version 14.0.0; LEAD Technologies Inc., Charlotte, NC, USA) was used for the statistical analysis. Allele frequencies were estimated by the 
maximum-likelihood approach. Deviation from the Hardy-Weinberg equilibrium was tested and rejected by using Pearson's $\chi^{2}$ test. Deviations from normal distribution were tested using the Shapiro-Wilk test. Differences between the three genotypic groups were tested by the KruskalWallis test. The Mann-Whitney $U$ test was used to test for significant association under a recessive model for the Ala allele. Fasting insulin sensitivity was expressed according to the homeostasis model assessment of insulin resistance (HOMA) using the following formula: HOMA = insulin $(\mu \mathrm{U} / \mathrm{ml}) *$ glucose $(\mathrm{mmol} / \mathrm{l}) / 22.5$ (Haffner et al. 1997). The area under the postprandial curves (AUC) was calculated using the following formula:

$\frac{y t_{0}+y t_{1}}{2} \times\left(t_{1}-t_{0}\right)+\frac{y t_{1}+y t_{2}}{2} \times\left(t_{2}-t_{1}\right)+\cdots \frac{y t_{n-1}+y t_{\mathrm{n}}}{2} \times\left(t_{n}-t_{n-1}\right)$

\section{Results}

The allele frequency was 0.85 for the proline allele and 0.15 for the alanine allele (Pro12Pro, $n$ 515; Pro12Ala, $n$ 176; Ala12Ala, $n$ 17). The non-obese subgroup with BMI $<30 \mathrm{~kg} / \mathrm{m}^{2}$ was made up of 555 subjects (Pro12Pro, $n$ 403; Pro12Ala, $n$ 141; Ala12Ala, $n$ 11).

\section{Total cohort}

Only LDL-cholesterol showed a normal distribution. All other anthropometric and metabolic parameters were not normally distributed (Table 1). PPAR genotypic groups did not significantly differ in weight, length, BMI, waist circumference, waist:hip ratio, blood pressure, pulse, cholesterol, HDL-cholesterol, LDL-cholesterol, fasting glucose, fasting insulin, fasting HOMA, fasting TAG and fasting NEFA when compared with all genotypes (Kruskal-Wallis test) (Table 1). Although postprandial parameters after an oral metabolic tolerance test tended to be lower in the PPAR $\gamma 2$ Ala12Ala homozygotes than in carriers of the PPAR $\gamma$ Pro12 genotype, no significance was attained (Table 1). When tested under a recessive model for the Ala allele (Pro12Pro + Pro12Ala $v$. Ala12Ala) fasting insulin levels were significantly lower in the Ala12Ala group (Mann-Whitney $U$ test).

\section{Non-obese sub-cohort}

Obesity is associated with insulin resistance and the development of type 2 diabetes. In order to evaluate the association of the PPAR $\gamma 2$ Pro12Ala polymorphism, irrespective of obesity, we carried out an association study in a non-obese sub-cohort $\left(\right.$ BMI $\left.<30 \mathrm{~kg} / \mathrm{m}^{2}\right)$. Because of the deviations from normal

Table 1. Anthropometric, fasting and postprandial blood parameters of different genotypes of the PPAR $\gamma 2$ Pro12Ala polymorphism (Mean values with their standard errors)

\begin{tabular}{|c|c|c|c|c|c|c|c|c|c|}
\hline \multirow[b]{2}{*}{ Parameter } & \multirow[b]{2}{*}{ n.d. } & \multicolumn{2}{|c|}{ Pro12Pro ( $n 515)$} & \multicolumn{2}{|c|}{ Pro12Ala $(n 176)$} & \multicolumn{2}{|c|}{ Ala12Ala $(n 17)$} & \multirow{2}{*}{$\begin{array}{c}\text { Global } \\
\text { test }\end{array}$} & \multirow{2}{*}{$\begin{array}{c}\text { Recessive } \\
\text { model }\end{array}$} \\
\hline & & Mean & SEM & Mean & SEM & Mean & SEM & & \\
\hline \multicolumn{10}{|l|}{ Anthropometric parameters } \\
\hline Age (years) & - & 59.09 & 0.24 & $58 \cdot 81$ & 0.42 & 57.47 & 1.39 & 0.477 & 0.243 \\
\hline Body weight $(\mathrm{kg})$ & - & $86 \cdot 15$ & 0.62 & $86 \cdot 12$ & $1 \cdot 121$ & $86 \cdot 7$ & 3.35 & 0.961 & 0.930 \\
\hline BMI $\left(\mathrm{kg} / \mathrm{m}^{2}\right)$ & - & $27 \cdot 36$ & 0.18 & 27.54 & 0.33 & $27 \cdot 53$ & 0.94 & 0.935 & 0.988 \\
\hline Waist circumference $(\mathrm{cm})$ & - & 99.95 & 0.54 & $100 \cdot 55$ & 0.94 & $99 \cdot 18$ & 3.36 & 0.800 & 0.505 \\
\hline Waist:Hip ratio $(\mathrm{cm} / \mathrm{cm})$ & - & 0.989 & 0.003 & 0.993 & 0.005 & 0.983 & 0.02 & 0.676 & 0.511 \\
\hline Systolic blood pressure $(\mathrm{mmHg})$ & - & 128.68 & 0.75 & 131.48 & 1.57 & $130 \cdot 29$ & 4.08 & 0.567 & 0.719 \\
\hline Diastolic blood pressure $(\mathrm{mmHg})$ & - & $80 \cdot 16$ & 0.45 & 81.59 & 0.91 & 80.00 & 3.00 & 0.512 & 0.670 \\
\hline Pulse (beats/min) & - & 68.06 & 0.48 & $69 \cdot 61$ & 0.83 & 67.41 & 2.56 & 0.226 & 0.831 \\
\hline \multicolumn{10}{|l|}{ Fasting papameters } \\
\hline Cholesterol $(\mathrm{mmol} / \mathrm{dl})$ & - & $5 \cdot 84$ & 0.046 & 5.94 & 0.08 & 5.92 & 0.44 & 0.621 & 0.730 \\
\hline $\mathrm{HDL}(\mathrm{mmol} / \mathrm{dl})$ & - & 1.38 & 0.017 & 1.40 & 0.03 & 1.40 & 0.09 & 0.740 & 0.672 \\
\hline $\mathrm{LDL}(\mathrm{mmol} / \mathrm{l})$ & + & 3.73 & 0.04 & $3 \cdot 71$ & 0.06 & $3 \cdot 81$ & 0.28 & 0.967 & 0.833 \\
\hline TAG (mmol/l) & - & 1.58 & 0.04 & 1.65 & 0.11 & 1.24 & 0.16 & 0.200 & 0.082 \\
\hline $\operatorname{NEFA}(\mathrm{mmol} / \mathrm{l})$ & - & 0.426 & 0.009 & 0.442 & 0.017 & 0.418 & 0.037 & 0.868 & 0.945 \\
\hline Glucose $(\mathrm{mmol} / \mathrm{l})$ & - & 5.82 & 0.04 & 5.82 & 0.08 & 5.65 & 0.17 & 0.903 & 0.658 \\
\hline Insulin (pmol//) & - & $103 \cdot 2$ & 3.83 & $103 \cdot 34$ & $6 \cdot 18$ & $77 \cdot 30$ & 11.39 & 0.090 & 0.039 \\
\hline $\mathrm{HOMA}(\mathrm{mmol} / \mathrm{l} * \mu \mathrm{U} / \mathrm{ml} / 22.5)$ & - & 4.05 & 0.19 & 4.07 & 0.32 & 2.91 & 0.51 & 0.144 & 0.064 \\
\hline \multicolumn{10}{|l|}{ OMTT } \\
\hline TAG (AUC mmol/l *h) & - & 19.51 & 0.43 & $19 \cdot 83$ & 1.09 & 15.99 & 1.80 & 0.293 & 0.155 \\
\hline NEFA (AUC mmol/l *h) & - & 4.403 & 0.056 & 4.333 & 0.098 & 3.99 & 0.239 & 0.290 & 0.159 \\
\hline Glucose AUC $(\mathrm{mmol} / \mathrm{l} * \mathrm{~h})$ & - & 29.07 & 0.26 & 28.92 & 0.36 & 28.81 & 1.01 & 0.923 & 0.874 \\
\hline Insulin (AUC pmol/l *h) & - & 1419.90 & 51.94 & 1441.99 & 93.02 & $1102 \cdot 38$ & $228 \cdot 6$ & 0.168 & 0.063 \\
\hline $\mathrm{HOMA}\left(\mathrm{mmol} / / * \mu \mathrm{U} / \mathrm{ml} / 22 \cdot 5^{*} \mathrm{~h}\right)$ & - & 60.25 & 2.93 & 59.88 & 4.79 & 47.29 & $12 \cdot 87$ & 0.274 & 0.119 \\
\hline \multicolumn{10}{|l|}{ OGTT } \\
\hline Glucose (AUC mmol/l *h) & - & 25.93 & 0.31 & $25 \cdot 72$ & 0.48 & $26 \cdot 81$ & 1.38 & 0.685 & 0.386 \\
\hline Insulin (AUC pmol// *h) & - & 1218.33 & $42 \cdot 83$ & 1199.77 & 69.84 & $915 \cdot 64$ & 137.6 & 0.224 & $0 \cdot 110$ \\
\hline $\mathrm{HOMA}(\mathrm{mmol} / \mathrm{l} * \mu \mathrm{U} / \mathrm{ml} / 22.5 * \mathrm{~h})$ & _- & $65 \cdot 10$ & $2 \cdot 84$ & 63.60 & 4.52 & $52 \cdot 38$ & 11.5 & 0.545 & 0.354 \\
\hline
\end{tabular}

Homozygote carriers of the wild-type genotype coding for proline (P12P), heterozygote carriers (P12A) and homozygote carriers of the alanine coding genotype (A12A). n.d., Normal distribution was tested using Shapiro-Wilk test; $(+)$ designates the presence of a normal distribution; $(-)$ not normal distribution. HOMA, homeostasis model assessment of insulin resistance; OMTT, oral metabolic tolerance test; OGTT, oral glucose tolerance test. AUC, area under the curve. Differences between the three genotypic groups were tested using Kruskal-Wallis test (global test). The Mann-Whitney $U$ test (recessive model) was used to test for significant association under a recessive model for the Ala allele. For details of subjects and procedures, see Research design and methods. 
distribution of anthropometric and most metabolic parameters, we could employ an adjustment for confounders possible for parametric methods.

\section{Anthropometric and fasting laboratory parameters}

Only body weight and LDL-cholesterol levels showed a normal distribution (Table 2). PPAR-genotypic groups did not significantly differ in weight, length, BMI, blood pressure, pulse, fasting cholesterol, fasting HDL-cholesterol, fasting LDL-cholesterol and fasting glucose (Table 2). The waist circumference, fasting $\mathrm{TAG}$, fasting insulin and fasting HOMA were significantly lower in the Ala12Ala group than in the Pro12Pro group (Table 2).

\section{Oral metabolic tolerance test}

Postprandial TAG levels differed significantly between genotypes (Fig. 1; Table 2). The individual maximum levels of postprandial TAG after the intake of mixed meals were significantly higher in the Pro12Pro group than in the Ala12Ala group.

Neither fasting NEFA nor postprandial NEFA differed significantly between genotypes. However, NEFA tended to be lower in the postprandial phase (Fig. 1; Table 2).
No differences were found for fasting and postprandial glucose plasma levels, although glucose levels tended to be lower in the Ala12Ala group (Fig. 1; Table 2).

Insulin levels were different in the fasting samples and, over the whole postprandial observation period, they measured up to $5 \mathrm{~h}$ postprandial (Fig. 1; Table 2).

The fasting and postprandial insulin sensitivity, expressed as HOMA, was lower in the Pro12Pro group than in the Ala12Ala group (Table 2).

In order to evaluate postprandial adiponectin levels of the nonobese sub-cohort, irrespective of the influence of BMI and age, we formed a BMI- and age-matched sub-cohort of the non-obese cohort. For the Ala12Ala homozygote carriers ( $n$ 11) age and BMI-matched partners of Pro12Pro ( $n 73)$ were included.

Neither fasting adiponectin (Pro12Pro, 5201 (SE 335) ng/ml; Ala12Ala, 4120 (SE 407) ng/ml) nor postprandial adiponectin (AUC: Pro12Pro, 39198 (SE 2503) ng/ml per h; Ala12Ala, 30963 (SE 3059) $\mathrm{ng} / \mathrm{ml}$ per h) differed significantly between genotypes, although adiponectin tended to be lower in the Ala12Ala group.

\section{Oral glucose tolerance test}

As shown in Fig. 2, neither glucose levels nor insulin levels differed between the Pro12Pro and Ala12Ala groups in postprandial plasma levels after the glucose load (Fig. 2; Table 1).

Table 2. Subgroup BMl $<30 \mathrm{~kg} / \mathrm{m}^{2}$. Anthropometric and fasting and postprandial blood parameters of different genotypes of the PPAR $\gamma 2$ Pro12Ala polymorphism

(Mean values with their standard errors)

\begin{tabular}{|c|c|c|c|c|c|c|c|c|c|}
\hline \multirow[b]{2}{*}{ Parameter } & \multirow[b]{2}{*}{ n.d. } & \multicolumn{2}{|c|}{ Pro12Pro ( $n$ 403) } & \multicolumn{2}{|c|}{ Pro12Ala (n 141) } & \multicolumn{2}{|c|}{ Ala12Ala (n11) } & \multirow{2}{*}{$\begin{array}{c}\text { Global } \\
\text { test }\end{array}$} & \multirow{2}{*}{$\begin{array}{c}\text { Recessive } \\
\text { model }\end{array}$} \\
\hline & & Mean & SEM & Mean & SEM & Mean & SEM & & \\
\hline \multicolumn{10}{|l|}{ Anthropometric parameters } \\
\hline Age (years) & - & $59 \cdot 39$ & 0.28 & $58 \cdot 90$ & 0.49 & $58 \cdot 27$ & 1.83 & 0.588 & 0.65 \\
\hline Body weight(kg) & + & $80 \cdot 57$ & 0.47 & $80 \cdot 69$ & 0.81 & 78.9 & 2.46 & 0.535 & 0.264 \\
\hline BMI $\left(\mathrm{kg} / \mathrm{m}^{2}\right)$ & - & $25 \cdot 56$ & 0.11 & $25 \cdot 74$ & 0.19 & 24.96 & 0.46 & $0 \cdot 194$ & 0.115 \\
\hline Waist circumference $(\mathrm{cm})$ & - & $95 \cdot 61$ & 0.40 & $95 \cdot 71$ & 0.68 & $90 \cdot 55$ & 1.82 & 0.052 & 0.015 \\
\hline Waist:Hip ratio $(\mathrm{cm} / \mathrm{cm})$ & - & 0.974 & 0.003 & 0.977 & 0.004 & 0.950 & 0.01 & 0.138 & 0.053 \\
\hline Systolic blood pressure (mmHg) & - & $125 \cdot 43$ & 0.81 & $128 \cdot 42$ & 1.61 & $128 \cdot 64$ & $5 \cdot 27$ & 0.363 & 0.712 \\
\hline Diastolic blood pressure $(\mathrm{mmHg})$ & - & $78 \cdot 28$ & 0.5 & 80.07 & 0.98 & 79.55 & $2 \cdot 9$ & 0.318 & 0.945 \\
\hline Pulse (beats/min) & - & $67 \cdot 32$ & 0.55 & 68.90 & 0.96 & 66.55 & 3.5 & $0 \cdot 164$ & 0.807 \\
\hline \multicolumn{10}{|l|}{ Fasting parameters } \\
\hline Cholesterol (mmol/dl) & - & 5.85 & 0.005 & $6 \cdot 00$ & 0.09 & $6 \cdot 04$ & 0.50 & 0.426 & 0.898 \\
\hline $\mathrm{HDL}(\mathrm{mmol} / \mathrm{dl})$ & - & 1.42 & 0.02 & 1.47 & 0.033 & 1.54 & 0.10 & $0 \cdot 179$ & 0.221 \\
\hline $\mathrm{LDL}(\mathrm{mmol} / \mathrm{l})$ & + & $3 \cdot 70$ & 0.042 & 3.72 & 0.07 & 3.82 & 0.29 & 0.937 & 0.891 \\
\hline TAG (mmol/l) & - & 1.49 & 0.04 & 1.59 & 0.12 & 0.99 & 0.12 & 0.06 & 0.02 \\
\hline NEFA $(\mathrm{mmol} / \mathrm{l})$ & - & 0.412 & 0.009 & 0.427 & 0.02 & 0.403 & 0.04 & 0.883 & 0.906 \\
\hline Glucose (mmol/l) & - & $5 \cdot 68$ & 0.04 & $5 \cdot 68$ & 0.07 & $5 \cdot 44$ & 0.21 & 0.568 & 0.294 \\
\hline Insulin $(p m o l / l)$ & - & $87 \cdot 58$ & $2 \cdot 85$ & $88 \cdot 41$ & $5 \cdot 21$ & $55 \cdot 21$ & $5 \cdot 21$ & 0.008 & 0.003 \\
\hline HOMA (mmol/l * $\mu \mathrm{U} / \mathrm{ml} / 22.5)$ & - & $3 \cdot 26$ & 0.12 & $3 \cdot 34$ & 0.26 & 1.96 & 0.24 & 0.016 & 0.005 \\
\hline \multicolumn{10}{|l|}{ OMTT } \\
\hline TAG (AUC mmol//*h) & - & $18 \cdot 78$ & 0.48 & $19 \cdot 44$ & $1 \cdot 29$ & $13 \cdot 30$ & 1.66 & $0 \cdot 131$ & 0.050 \\
\hline NEFA (AUC mmol//*h) & - & $4 \cdot 27$ & 0.06 & $4 \cdot 19$ & $0 \cdot 10$ & 3.76 & 0.18 & 0.268 & 0.142 \\
\hline Glucose AUC (mmol/l*h) & - & 28.05 & 0.26 & $28 \cdot 15$ & 0.31 & $27 \cdot 13$ & 0.64 & 0.509 & 0.454 \\
\hline Insulin (AUC pmol//*h) & - & $1189 \cdot 98$ & $36 \cdot 17$ & $1215 \cdot 17$ & $81 \cdot 28$ & $735 \cdot 40$ & $108 \cdot 6$ & 0.028 & 0.009 \\
\hline HOMA (mmol/l * $\mu \mathrm{U} / \mathrm{ml} / 22 \cdot 5 * \mathrm{~h})$ & - & $46 \cdot 63$ & 1.69 & $48 \cdot 40$ & $4 \cdot 35$ & $27 \cdot 40$ & 4.55 & 0.054 & 0.019 \\
\hline \multicolumn{10}{|l|}{ OGTT } \\
\hline Glucose (AUC mmol//*h) & - & 25.06 & 0.32 & $24 \cdot 85$ & 0.43 & 25.53 & 1.07 & 0.678 & 0.382 \\
\hline Insulin (AUC pmol/I*h) & - & $1033 \cdot 43$ & $30 \cdot 70$ & $1046 \cdot 51$ & 61.53 & $802 \cdot 29$ & $90 \cdot 47$ & 0.996 & 0.690 \\
\hline HOMA (mmol//* $\left.\mu \mathrm{U} / \mathrm{ml} / 22 \cdot 5^{\star} \mathrm{h}\right)$ & - & $52 \cdot 40$ & 1.96 & 54.08 & $4 \cdot 25$ & $42 \cdot 53$ & $5 \cdot 77$ & 0.729 & 0.691 \\
\hline
\end{tabular}

Homozygote carriers of the wild-type genotype coding for proline $(\mathrm{P} 12 \mathrm{P})$, heterozygote carriers $(\mathrm{P} 12 \mathrm{~A})$ and homozygote carriers of the alanine coding genotype $(\mathrm{A} 12 \mathrm{~A})$. n.d., Normal distribution was tested using Shapiro-Wilk test; $(+)$ designates the presence of a normal distribution, $(-)$ not normal distribution. HOMA, homeostasis model assessment of insulin resistance; OMTT, oral metabolic tolerance test; OGTT, oral glucose tolerance test. AUC, area under the curve. Differences between the three genotypic groups were tested using Kruskal-Wallis test (global test). The Mann-Whitney $U$ test (recessive model) was used to test for significant association under a recessive model for the Ala allele. For details of subjects and procedures, see Research design and methods. 

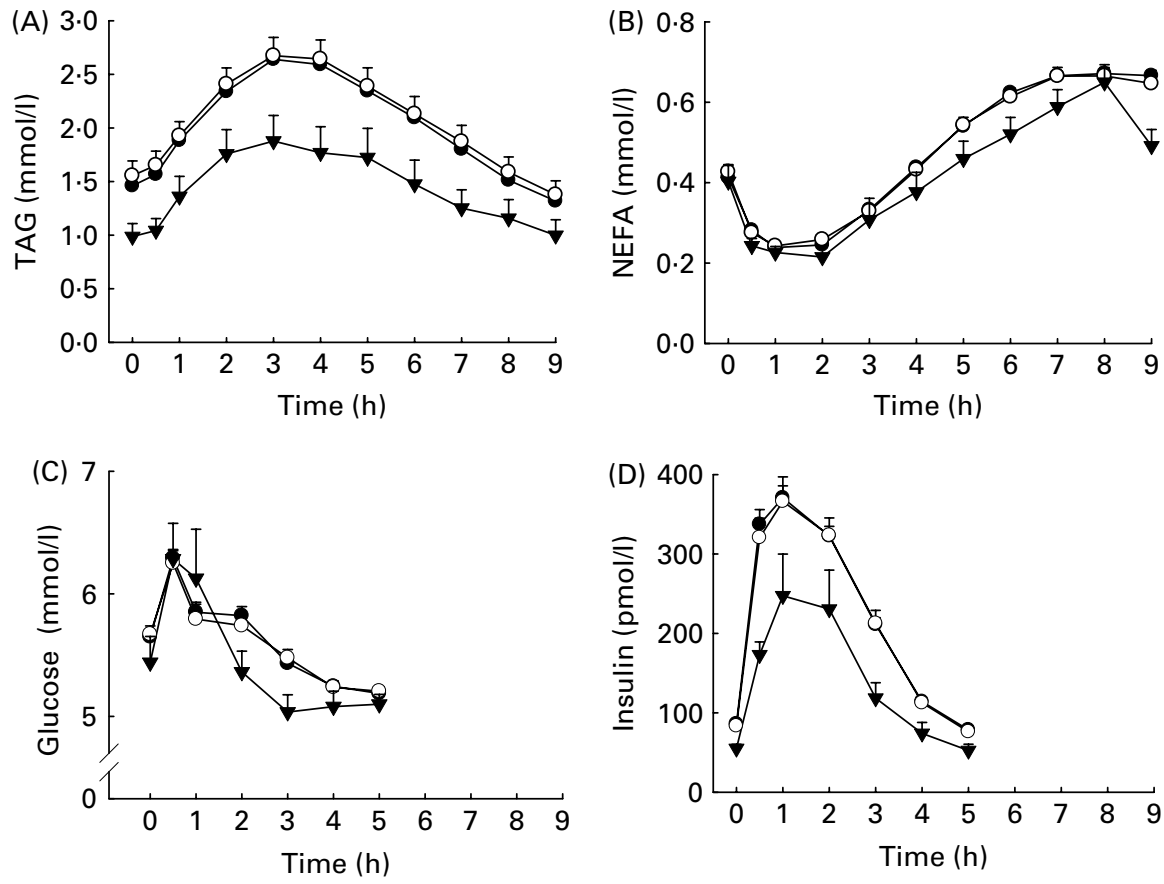

Fig. 1. Postprandial blood levels of the non-obese subgroup $\left(B M I<30 \mathrm{~kg} / \mathrm{m}^{2}\right)$ after a mixed meal (oral metabolic tolerance test, OMTT). Data are presented as means with their standard errors. PPAR $\gamma 2$ Pro12Pro, - --; PPAR $\gamma 2$ Pro12Ala, -O-; PPAR $\gamma 2$ Ala12Ala, - $\mathbf{-}-$. (A) Postprandial TAG-curve after ingestion of a mixed meal; (B) postprandial serum levels of NEFA after OMTT; (C) postprandial glucose levels after OMTT; (D) postprandial insulin levels after OMTT.

\section{Discussion}

In non-obese males, we were able to show an association between PPAR 22 Ala12Ala homozygosity and lower fasting and lower postprandial TAG levels (AUC) after a mixed
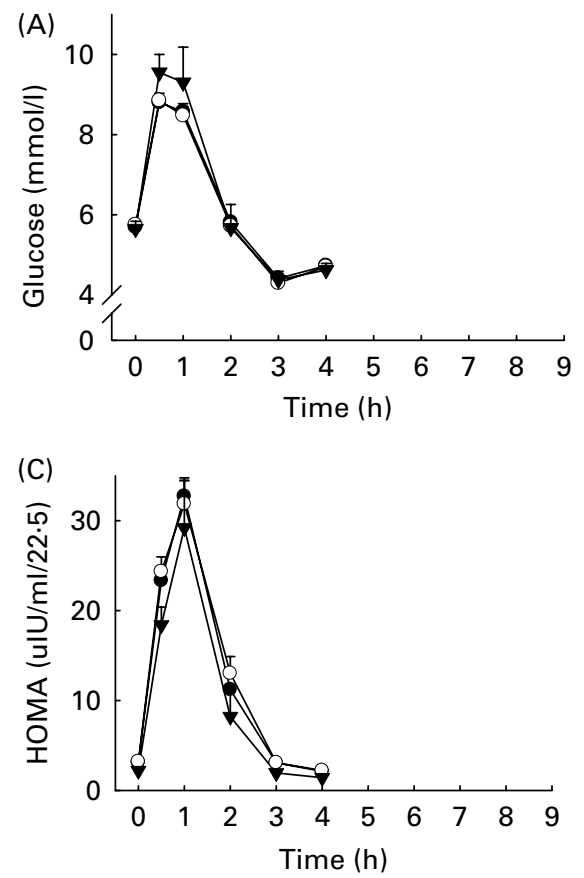

meal (Fig. 1). Furthermore, PPAR 2 Ala12Ala was associated with lower fasting insulin levels, lower postprandial insulin levels (AUC) and higher postprandial insulin sensitivity (HOMA AUC) after the intake of a fat-containing meal

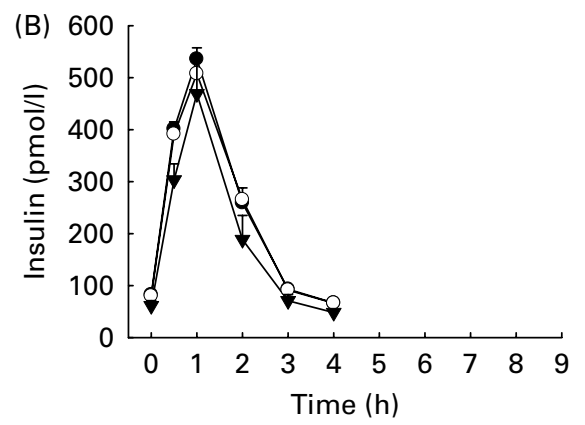

Fig. 2. Postprandial blood levels of the non-obese subgroup (BMI $<30 \mathrm{~kg} / \mathrm{m}^{2}$ ) after a glucose load (oral glucose tolerance test, OGTT). Data are presented as

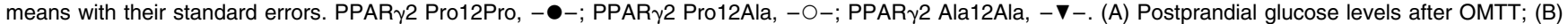
Postprandial insulin levels after OMTT; (C) Postprandial homeostasis model assessment of insulin resistance levels (HOMA) after OGTT. For details of subjects and procedures, see Research design and methods. 
(Fig. 1). This, however, was not observed after an oral glucose load (Fig. 2). In non-obese males, a lower waist circumference was found in the Ala12Ala group compared with the Pro12Pro group, despite equal BMI values (Table 2).

Subjects with the Pro12Ala genotype had values similar to those with the Pro12Pro genotype (Tables 1 and 2; Fig. 1). Up until now, only three studies have calculated the Ala12Ala genotype separately, probably because of the low frequency of this genotype (Valve et al. 1999; Frederiksen et al. 2002; Temelkova-Kurktschiev et al. 2004). As in the present study, in these studies, the Ala12Ala genotype clearly differed from the Pro12Ala and Pro12Pro genotype with regard to BMI (Valve et al. 1999), blood pressure and TAG (Frederiksen et al. 2002), and intima thickness (Temelkova-Kurktschiev et al. 2004), whereas the difference between Ala12 carriers and Pro12Pro homozygotes was less pronounced than as described by other studies (Altshuler et al. 2000).

In concordance with the present study, Poirier et al. (2000) did not find a different glucose and insulin response to a glucose load between the different genotypes. However, whereas they also did not find a different response to a lipid load, we did find a different response to a mixed meal containing fat. This difference was only detected by comparing the homozygous carriers of the rare Ala12Ala genotype with Pro12 carriers. Poirier and co-workers examined men aged 18 to 28 years from eleven different European countries, whereas the present study focused on men aged 45 to 65 years from one region. In the Bogalusa Heart study, Li et al. (2003) showed that differences in the association to insulin resistance in Ala12 carriers depended on the individual's age. While significant differences were found between homozygous wild-type carriers and carriers of the alanine coding allele (homozygote and heterozygote) for insulin resistance in adults, only insignificant trends were seen in young people ( $\mathrm{Li}$ et al. 2003). Furthermore, the heterogeneous origin of the participants and their dietary habits (Mediterranean diet in the south and more saturated fat in the north) may obscure phenotypic differences between genotypes. The association between the Pro12Ala polymorphism and BMI and insulin levels seems to depend on the ingestion of unsaturated fatty acids (Luan et al. 2001).

Recently, Vänttinen et al. (2005) showed that the glucose uptake of the whole body and the skeletal muscle is higher in Ala12 carriers than in the Pro12Pro group after a euglycaemic clamp. However, this higher insulin sensitivity was found only in non-obese and not in obese subjects (Vänttinen et al. 2005). We were able to confirm these findings in the cohort presented here after a mixed meal, where we only found significant differences between Ala12Ala genotypes and Pro12 carriers when obese subjects were excluded.

In the present study, weight and BMI were not affected by the polymorphism. However, waist circumference was lower in the Ala12Ala group. This is in agreement with the findings of Gonzalez-Sanchez et al. (2002), who showed that Pro12Pro homozygotes have centrally distributed fat and that Ala12 carriers have more peripheral fat distribution. Since visceral fat is assumed to be the driving force behind the development of insulin resistance (Giorgino et al. 2005), one might argue that the higher insulin sensitivity of the Ala12Ala group could be caused by lower abdominal fat. Visceral adipose tissue releases NEFA, which first pass the liver where they may be incorporated into VLDL more easily. Fasting NEFA, however, did not differ either in the Ala12Ala or in the Pro12carriers of the total or the non-obese group (Fig. 1). In contrast with this, postprandial NEFA tended to be lower (Fig. 1). This may suggest that NEFA were released more slowly by lipoprotein lipase from postprandial-affluent TAG-rich lipoproteins. Indeed, the expression of lipoprotein lipase, and in particular adipocyte LDL, is regulated by PPAR $\gamma$ (Schoonjans et al. 1996). This may explain why the PPAR $\gamma 2$ Pro12Ala polymorphism may have an impact on postprandial NEFA release from TAG-rich lipoproteins, although it is quite specifically expressed in adipose tissue (Desvergne \& Wahli, 1999). The data obtained by Tan et al. (2006), however, do not seem to support the theory that dietary fat causes a different release of NEFA. Interestingly, they found a faster NEFA clearance by muscle tissue (Tan et al. 2006). Accordingly, Vänttinen et al. (2005) found that the glucose uptake of the whole body and the skeletal muscle is increased in Ala12 carriers, compared with Pro12Pro homozygotes in a euglycaemic clamp. Stefan et al. (2001) showed that the intravenous infusion of fatty acids leads to an increase in the insulin resistance of the Pro12Pro group and a decrease in the insulin resistance of the Ala12 carriers. This explains why we found no differences in insulin sensitivity between Ala12Ala and Pro12-carrier homozygotes after a pure carbohydrate load (oral glucose tolerance test) (Fig. 2), whereas such a difference became overt after a fat-containing mixed meal (Fig. 1). Since PPAR $\gamma 2$ is quite specifically expressed by adipose tissue (Desvergne \& Wahli, 1999), we postulate that a factor
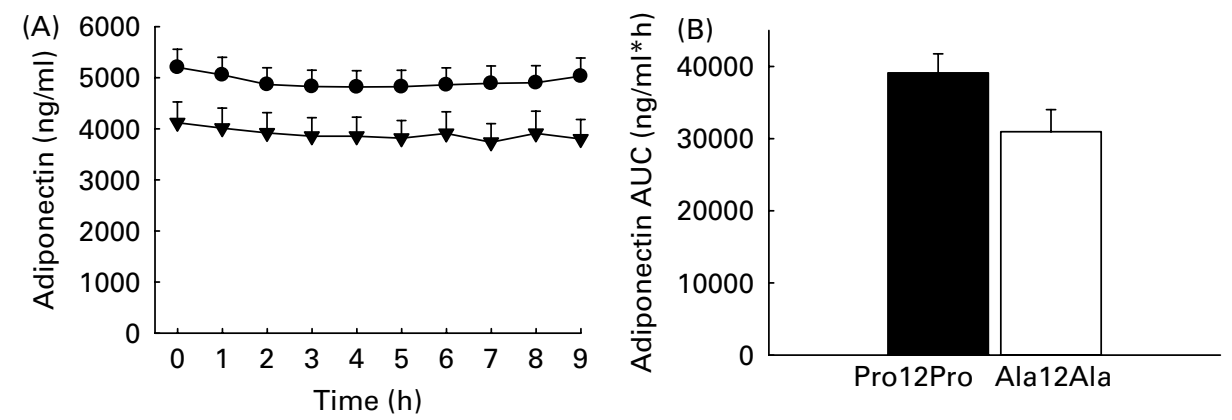

Fig. 3. Postprandial blood levels of the non-obese BMI-matched subgroup after a mixed meal (oral metabolic tolerance test, OMTT). Data are presented as means with their standard errors. PPAR 2 Pro12Pro, -- -; PPAR 2 Ala12Ala, - $\mathbf{-}-$. (A) Postprandial adiponectin levels after OMTT; (B) postprandial adiponectin levels area under the curve (AUC) of homozygote carriers. For details of subjects and procedures, see Research design and methods. 
released by adipocytes causes this PPAR $\gamma 2$ genotypic dependence of the fatty acid-mediated effect on insulin sensitivity. Therefore, we investigated the peripheral blood levels of an adipocyte factor, which is under regulatory control of PPAR $\gamma$ and has an influence on insulin sensitivity. The adipokine adiponectin - which increases insulin sensitivity - met this claim (Yamauchi et al. 2001). Fasting and postprandial adiponectin levels in the BMI-matched sub-cohort did not significantly differ between the Pro12Pro and the Ala12Ala group (Fig. 3). They even tended towards lower levels in the Ala12Ala group (Fig. 3). Yamamoto et al. (2002) recently also found reduced fasting adiponectin levels in Ala12 carriers, compared with Pro12Pro carriers. They subsumed that this finding provides evidence that the PPAR $\gamma 2$ Pro12Ala polymorphism has a functional impact on adipocyte tissue because this single nucleotide polymorphism is associated with decreased activity and results, therefore, in decreased PPAR $\gamma$-dependent adiponectin levels (Yamamoto et al. 2002).

The causative PPAR $\gamma$-dependent adipocyte-derived factor, which regulates insulin metabolism depending on the ingested meal, remains to be discovered from approximately fifty adipokines known at present (Trayhurn \& Wood, 2004).

In conclusion, PPAR $\gamma 2$ Ala12Ala is associated with lower fasting and postprandial TAG levels, lower insulin levels and higher postprandial insulin sensitivity after a mixed meal containing fat. In contrast with this, postprandial insulin levels and insulin sensitivity were not affected after an oral glucose load. This may indicate that the effects of PPAR $\gamma 2$ on insulin sensitivity are mediated by postprandial-affluent dietary fat and that the PPAR $\gamma 2$ polymorphism has some functional impact on postprandial metabolism. Since PPAR $\gamma 2$ is predominantly expressed in adipocytes, we postulate that a PPAR $\gamma 2$ and fatty acid-dependent adipocyte factor affects insulin sensitivity. NEFA and adiponectin were excluded as causative adipokines.

\section{Acknowledgements}

This work was supported by a BMBF (Federal Ministry of Education and Research) grant 'Dietary fat and metabolism, gene variability, regulation and function', AZ 0312823 A/B and a BMBF grant to MN (0313437A).

\section{References}

Altshuler D, Hirschhorn JN, Klannemark M, et al. (2000) The common PPARgamma Pro12Ala polymorphism is associated with decreased risk of type 2 diabetes. Nat Genet 26, 76-80.

American Diabetes Association (2004) Screening for type 2 diabetes. Diabetes Care 27, S11-S14.

Brandt JM, Djouadi F \& Kelly DP (1998) Fatty acids activate transcription of the muscle carnitine palmitoyltransferase I gene in cardiac myocytes via the peroxisome proliferator-activated receptor alpha. J Biol Chem 273, 23786-23792.

Darimont C, Gradoux N, Cumin F, Baum HP \& De Pover A (1998) Differential regulation of intestinal and liver fatty acid-binding proteins in human intestinal cell line (Caco-2): role of collagen. Exp Cell Res 244, 441-447.

Desvergne B \& Wahli W (1999) Peroxisome proliferator-activated receptors: nuclear control of metabolism. Endocr Rev 20, 649-688.
Ek J, Andersen G, Urhammer SA, et al. (2001) Studies of the Pro12Ala polymorphism of the peroxisome proliferator-activated receptorgamma2 (PPAR-gamma2) gene in relation to insulin sensitivity among glucose tolerant caucasians. Diabetologia 44, 1170-1176.

Frederiksen L, Brodbaek K, Fenger M, Jorgensen T, Borch-Johnsen K, Madsbad S \& Urhammer SA (2002) Comment: studies of the Pro12Ala polymorphism of the PPAR-gamma gene in the Danish MONICA cohort: homozygosity of the Ala allele confers a decreased risk of the insulin resistance syndrome. J Clin Endocrinol Metab 87, 3989-3992.

Giorgino F, Laviola L \& Eriksson JW (2005) Regional differences of insulin action in adipose tissue: insights from in vivo and in vitro studies. Acta Physiol Scand 183, 13-30.

Gonzalez-Sanchez JL, Serrano Rios M, Fernandez Perez C, Laakso M \& Martinez Larrad MT (2002) Effect of the Pro12Ala polymorphism of the peroxisome proliferator-activated receptor gamma-2 gene on adiposity, insulin sensitivity and lipid profile in the Spanish population. Eur J Endocrinol 147, 495-501.

Haffner SM, Miettinen H \& Stern MP (1997) The homeostasis model in the San Antonio Heart Study. Diabetes Care 20, 1087-1092.

Hampe J, Shaw SH, Saiz R, et al. (1999) Linkage of inflammatory bowel disease to human chromosome 6p. Am J Hum Genet $\mathbf{6 5}$, $1647-1655$.

Hertz R, Bishara-Shieban J \& Bar-Tana J (1995) Mode of action of peroxisome proliferators as hypolipidemic drugs. Suppression of apolipoprotein C-III. J Biol Chem 270, 13470-13475.

Issemann I, Prince R, Tugwood J \& Green S (1992) A role for fatty acids and liver fatty acid binding protein in peroxisome proliferation? Biochem Soc Trans 20, 824-827.

Jacob S, Stumvoll M, Becker R, et al. (2000) The PPARgamma2 polymorphism pro12Ala is associated with better insulin sensitivity in the offspring of type 2 diabetic patients. Horm Metab Res 32, $413-416$

Jiang C, Ting AT \& Seed B (1998) PPAR-gamma agonists inhibit production of monocyte inflammatory cytokines. Nature 391, $82-86$.

Koch M, Rett K, Maerker E, Volk A, Haist K, Deninger M, Renn W \& Haring HU (1999) The PPARgamma2 amino acid polymorphism Pro 12 Ala is prevalent in offspring of type II diabetic patients and is associated to increased insulin sensitivity in a subgroup of obese subjects. Diabetologia 42, 758-762.

Lahti-Koski M, Pietinen P, Mannisto S \& Vartiainen E (2000) Trends in waist-to-hip ratio and its determinants in adults in Finland from 1987 to 1997. Am J Clin Nutr 72, 1436-1444.

Li S, Chen W, Srinivasan SR, Boerwinkle E \& Berenson GS (2003) The peroxisome proliferator-activated receptor-gamma2 gene polymorphism (Pro12Ala) beneficially influences insulin resistance and its tracking from childhood to adulthood: the Bogalusa Heart Study. Diabetes 52, 1265-1269.

Li Y \& Lazar MA (2002) Differential gene regulation by PPARgamma agonist and constitutively active PPARgamma2. Mol Endocrinol 16, 1040-1048.

Luan J, Browne PO, Harding AH, Halsall DJ, O'Rahilly S, Chatterjee VK \& Wareham NJ (2001) Evidence for gene-nutrient interaction at the PPARgamma locus. Diabetes 50, 686-689.

Mascaro C, Acosta E, Ortiz JA, Marrero PF, Hegardt FG \& Haro D (1998) Control of human muscle-type carnitine palmitoyltransferase I gene transcription by peroxisome proliferator-activated receptor. J Biol Chem 273, 8560-8563.

Nitz I, Doring F, Schrezenmeir J \& Burwinkel B (2005) Identification of new acyl-CoA binding protein transcripts in human and mouse. Int J Biochem Cell Biol 37, 2395-2405.

Poirier O, Nicaud V, Cambien F \& Tiret L (2000) The Pro12Ala polymorphism in the peroxisome proliferator-activated receptor gamma2 gene is not associated with postprandial responses to glucose or fat tolerance tests in young healthy subjects: the European Atherosclerosis Research Study II. J Mol Med 78, 346-351. 
Roden M, Price TB, Perseghin G, Petersen KF, Rothman DL, Cline GW \& Shulman GI (1996) Mechanism of free fatty acid-induced insulin resistance in humans. $J$ Clin Invest 97, 2859-2865.

Schoonjans K, Peinado-Onsurbe J, Lefebvre AM, Heyman RA, Briggs M, Deeb S, Staels B \& Auwerx J (1996) PPARalpha and PPARgamma activators direct a distinct tissue-specific transcriptional response via a PPRE in the lipoprotein lipase gene. Embo $J$ 15, 5336-5348.

Schoonjans K, Watanabe M, Suzuki H, Mahfoudi A, Krey G, Wahli W, Grimaldi P, Staels B, Yamamoto T \& Auwerx J (1995) Induction of the acyl-coenzyme A synthetase gene by fibrates and fatty acids is mediated by a peroxisome proliferator response element in the C promoter. J Biol Chem 270, 19269-19276.

Schrezenmeir J, Weber P, Probst R, Biesalski HK, Luley C, Prellwitz W, Krause U \& Beyer J (1992) Postprandial pattern of triglyceriderich lipoprotein in normal-weight humans after an oral lipid load: exaggerated triglycerides and altered insulin response in some subjects. Ann Nutr Metab 36, 186-196.

Sewter C \& Vidal-Puig A (2002) PPARgamma and the thiazolidinediones: molecular basis for a treatment of 'Syndrome X'? Diabetes Obes Metab 4, 239-248.

Spiegelman BM (1998) PPAR-gamma: adipogenic regulator and thiazolidinedione receptor. Diabetes 47, 507-514.

Stefan N, Fritsche A, Haring H \& Stumvoll M (2001) Effect of experimental elevation of free fatty acids on insulin secretion and insulin sensitivity in healthy carriers of the Pro12Ala polymorphism of the peroxisome proliferator-activated receptor-gamma2 gene. Diabetes 50, $1143-1148$.

Stumvoll M \& Haring H (2002) Reduced lipolysis as possible cause for greater weight gain in subjects with the Pro12Ala polymorphism in PPARgamma2? Diabetologia 45, 152-153.

Tan GD, Neville MJ, Liverani E, Humphreys SM, Currie JM, Dennis L, Fielding BA \& Karpe F (2006) The in vivo effects of the Pro12Ala PPARgamma2 polymorphism on adipose tissue NEFA metabolism: the first use of the Oxford Biobank. Diabetologia 49, 158-168.

Temelkova-Kurktschiev THM, Chinetti G, Zawadzki C, Haulon S, Kubaszek A, Koehler C, Leonhardt W, Staels B \& Laakso M (2004) AlAla12Alala genotype of the peroxisome proliferator-activated receptor gamma2 protects against atherosclerosis. J Clin Endocrinol Metab 89, 4238-4242.

Tontonoz P, Hu E, Graves RA, Budavari AI \& Spiegelman BM (1994) mPPAR gamma 2: tissue-specific regulator of an adipocyte enhancer. Genes Dev 8, 1224-1234.
Trayhurn P \& Wood IS (2004) Adipokines: inflammation and the pleiotropic role of white adipose tissue. Br J Nutr 92, 347-355.

Vaccaro O, Mancini FP, Ruffa G, Sabatino L, Iovine C, Masulli M, Colantuoni V \& Riccardi G (2002) Fasting plasma free fatty acid concentrations and Pro12Ala polymorphism of the peroxisome proliferator-activated receptor (PPAR) gamma2 gene in healthy individuals. Clin Endocrinol (Oxf) 57, 481-486.

Valve R, Sivenius K, Miettinen R, Pihlajamaki J, Rissanen A, Deeb SS, Auwerx J, Uusitupa M \& Laakso M (1999) Two polymorphisms in the peroxisome proliferator-activated receptor-gamma gene are associated with severe overweight among obese women. J Clin Endocrinol Metab 84, 3708-3712.

Vänttinen M, Nuutila P, Pihlajamaki J, et al. (2005) The effect of the Ala12 allele of the peroxisome proliferator-activated receptorgamma2 gene on skeletal muscle glucose uptake depends on obesity: a positron emission tomography study. J Clin Endocrinol Metab 90, 4249-4254.

Vidal-Puig AJ, Considine RV, Jimenez-Linan M, Werman A, Pories WJ, Caro JF \& Flier JS (1997) Peroxisome proliferator-activated receptor gene expression in human tissues. Effects of obesity, weight loss, and regulation by insulin and glucocorticoids. J Clin Invest 99, 2416-2422.

World Health Organization (1995) Physical status: the use and interpretation of anthropometry. Report of a WHO Expert Committee. World Health Organ Tech Rep Ser 854, 1-452.

Yamamoto Y, Hirose H, Miyashita K, Nishikai K, Saito I, Taniyama M, Tomita M \& Saruta T (2002) PPAR(gamma)2 gene Pro12Ala polymorphism may influence serum level of an adipocyte-derived protein, adiponectin, in the Japanese population. Metabolism 51, 1407-1409.

Yamauchi T, Kamon J, Waki H, et al. (2001) The fat-derived hormone adiponectin reverses insulin resistance associated with both lipoatrophy and obesity. Nat Med 7, 941-946.

Yen CJ, Beamer BA, Negri C, Silver K, Brown KA, Yarnall DP, Burns DK, Roth J \& Shuldiner AR (1997) Molecular scanning of the human peroxisome proliferator activated receptor gamma (hPPAR gamma) gene in diabetic Caucasians: identification of a Pro12Ala PPAR gamma 2 missense mutation. Biochem Biophys Res Commun 241, 270-274.

Yu GS, Lu YC \& Gulick T (1998) Co-regulation of tissue-specific alternative human carnitine palmitoyltransferase Ibeta gene promoters by fatty acid enzyme substrate. J Biol Chem 273, $32901-32909$. 